\title{
DEDUCTIBLE MEDICAL EXPENSES FOR INCOME TAX PURPOSES: TRADITIONAL HEALERS, PHARMACISTS AND COSMETIC PROCEDURES
}

\author{
Fanie van $\mathrm{Zyl}$ \\ LLB LLM \\ Senior Lecturer, Department of Mercantile Law \\ University of South Africa (UNISA)
}

SUMMARY

In terms of section 18(1)(b)(i) of the Income Tax Act 58 of 1962 a taxpayer is entitled to a qualifying medical-expenses deduction for services rendered by a registered medical practitioner specifically listed in subparagraph (i). Since the promulgation of the Traditional Health Practitioners Act 35 of 2004 and the later Traditional Health Practitioners Act 22 of 2007 (which replaced the earlier unconstitutional act), section 18 (1)(b)(i) has not been amended to provide a qualifying medical-expenses deduction to a taxpayer who consulted a traditional healer instead of a medical practitioner as listed in subparagraph (i). This article attempts to show that no such amendment is needed. The taxpayer can avail himself of the burden of proof to make a qualifying medical-expenses deduction for services rendered by a traditional healer by applying an expansive interpretation to the words "medical practitioner". This article furthermore discusses the interpretation problems as a result of the vague meaning of "professional services" and the subsequent possibility to deduct cosmetic expenses as qualifying medical expenses. Lastly, this article discusses the situation where a taxpayer wishes to make a qualifying medical-expenses deduction for schedule 2 medicines prescribed and supplied by a pharmacist, which, it seems, is not allowed.

INTRODUCTION

As a decade of traditional medicine in Africa ${ }^{1}$ is nearing its end, it is rather alarming to note that a large number of South Africans has never made the paradigm shift from apartheid-indoctrinated beliefs to a philosophy where there is equality and tolerance towards different religions and cultural values. South Africa is in a phase where traditional customs need to be recognized, be given legal effect and protected to balance the unjust ignorance of these customs in the past. One of these customs is a respect for the healing powers of traditional healers or sangomas that have for long been ignored

The African Union adopted the decade of traditional medicine in Africa at the Lusaka Summit held in June 2001. 
as a medical service by a predominantly Western society. On 11 February 2005, the Traditional Health Practitioners Act 35 of $2004^{2}$ was promulgated. This marked a landmark change, for the Act recognized sangomas as legal traditional healers and regulated the traditional-healing industry for the first time. This article will scrutinize the traditional-healing profession from an income tax perspective. The main purpose of this article is to determine whether a taxpayer who prefers to consult a sangoma instead of a registered conventional ${ }^{3}$ health practitioner is entitled to a deduction for the sangoma's fee in terms of section 18(1)(b)(i) of the Income Tax Act 58 of 1962. This article will draw an analogy between a "medical practitioner" as contemplated in the Income Tax Act and traditional healers and will suggest that section 18(1)(b)(i) can be interpreted to include traditional-health practitioners as "medical practitioners". This article will furthermore investigate policy concerns regarding the inclusion of traditional healers as medical practitioners for purposes of section 18(1)(b)(i). In addition this article will consider whether a taxpayer is entitled to claim a deduction for cosmetic surgery and/or for services rendered or medicines prescribed and supplied by a pharmacist.

\section{BACKGROUND}

In South Africa a taxpayer who is a natural person is allowed to deduct from gross income, certain medical expenses in respect of $\mathrm{him}^{4}$, his spouse, children or dependant(s) who is (are) also listed as a dependant(s) in terms of the taxpayer's medical-aid scheme. ${ }^{5}$

A taxpayer may deduct (for the 2009/2010 year of assessment) contributions made by himself to a medical-aid scheme limited to R625 per month in respect of the taxpayer; R1250 per month for the taxpayer and one dependant; and R380 per month for any additional dependant. ${ }^{6}$ These amounts are adjusted annually prior to the commencement of a new year of assessment. In the case of a taxpayer over the age of 65 and who is entitled to a rebate under section 6(2)(b), there is no limitation on the medical-aid contribution deduction. Where the taxpayer, his spouse or dependant is "disabled" as contemplated in section 18(3) of the Act, no limitation will apply

2 The Traditional Health Practitioners Act 22 of 2007 was later promulgated to replace the unconstitutional Traditional Health Practitioners Act 35 of 2004.

3 For purposes of this article "conventional" shall mean the Western or generally accepted norms and standards applied to the medical profession. It excludes all medical professions that would generally be perceived as strange or unacceptable by a western orientated or developed society.

4 Reference to "male" includes the "female" unless otherwise stated.

5 S 18(1)(a) and (b) Act 58 of 1962; Jordaan, Koekemoer, Stiglingh, Van Schalkwyk, Wasserman and Wilcocks et al Silke: South African Income Tax 2008 (2008) 255; Huxham and Haupt Notes on South African Income Tax 27ed (2008) 198; Burt "Benefits for the Sick" 2005 Tax Planning 151; Meyerowitz Meyerowitz on Income Tax 2007/2008 (2008) par 16.23; Author unknown "Medical Expenses: What can you Deduct?" 2009 Professional Accountant 28-29; and Jones "Medical Claims not Clear-cut: Tax" 2008 Personal Finance Newsletter 15.

6 S 18(2)(c)(i)(aa)-(cc); Stiglingh, De Swardt, Jordaan, Koekemoer, Van Schalkwyk and Wilcocks Silke:Suid-Afrikaanse Inkomstebelasting (2010) 351; Sacks "What can you Claim under our Tax Regime?" 2008 Taxtalk 20; and Jones 2008 Personal Finance Newsletter 15.

7 S 18(2)(a). 
to the medical-aid contribution deduction for that specific disabled taxpayer, spouse or dependant. ${ }^{8}$

In addition to the medical-aid contribution deduction, a taxpayer may deduct qualifying medical expenses that exceed $7,5 \%{ }^{9}$ of his taxable income $^{10}$ (taxable income in this sense excludes any retirement fund lump sum benefit and retirement fund lump sum withdrawal benefit), which was actually paid during the year of assessment, ${ }^{11}$ from his gross income. Qualifying medical expenses include inter alia any irrecoverable amount that was actually paid by the taxpayer to a

“(i) medical practitioner, dentist, optometrist, homeopath, naturopath, osteopath, herbalist, physiotherapist, chiropractor or orthopaedist for professional services rendered or medicines supplied to the taxpayer, his or her spouse or his or her children, or any dependant of the taxpayer if the taxpayer was a member of a scheme or fund contemplated in paragraph (a) and that dependant was, at the time such amounts were paid, admitted as a dependant of the taxpayer in terms of that scheme or fund; or

(ii) nursing home or hospital or any duly registered or enrolled nurse, midwife or nursing assistant (or to any nursing agency in respect of the services of such a nurse, midwife or nursing assistant) in respect of the illness or confinement of the taxpayer, his or her spouse or his or her children, or any dependant of the taxpayer contemplated in subparagraph (i); or

(iii) pharmacist for medicines supplied on the prescription of any person mentioned in subparagraph (i) for the taxpayer, his or her spouse or his or her children, or any dependant of the taxpayer contemplated in subparagraph ...."

In the case of a taxpayer over the age of 65 who is entitled to a rebate under section 6(2)(b), the total amount (with no limitation) of the qualifying medical expenses that were actually incurred will qualify as an allowable deduction. ${ }^{13}$ In the case where the taxpayer, his/her spouse or dependant is a disabled person as defined in section 18(3) of the Act, the total amount of the qualifying medical expenses in relation to the disabled person who qualify as an allowable deduction. ${ }^{14}$

Any medical-aid scheme contribution or qualifying medical expenses incurred by the estate of a deceased taxpayer is deemed to have been incurred by the taxpayer on the day before his death. ${ }^{15}$

It is clear that where an amount was paid for medical services as contemplated in section 18(1)(b), a deduction will be allowed only if the expenses cannot be recovered from the taxpayer's (or spouse's) medical-aid

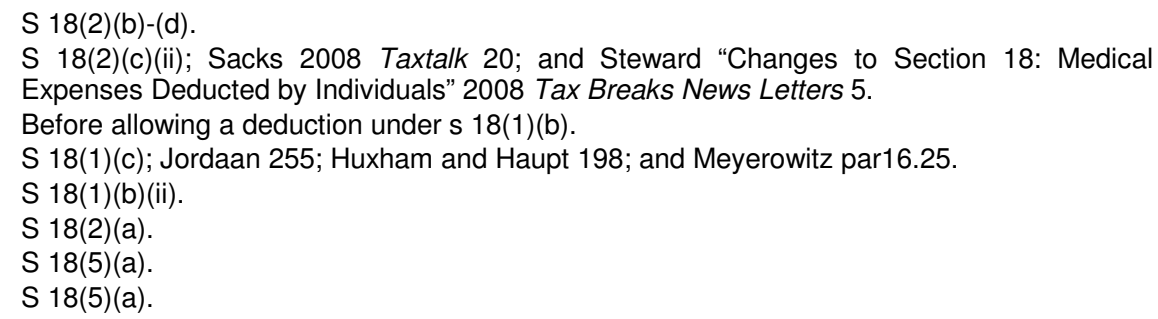


scheme or any other insurance policy. In other words the expense must have been paid out of the taxpayer's own pocket. ${ }^{16}$

\section{TRADITIONAL HEALERS}

\section{Can you deduct sangoma fees from your gross income?}

In summary a three-tier test is used to determine whether medical expenses will qualify as qualifying medical expenses, namely:

(i) the expense must have been incurred for services rendered;

(ii) by a duly registered medical practitioner;

(iii) listed as a medical practitioner in terms of section 18(1)(b)(i).

Each element of the three-tier test will be discussed to determine if a taxpayer who has consulted a traditional healer will be entitled to a qualifying medical-expense deduction in terms of section 18(1)(b)(i).

For decades, traditional healers have not been recognized under South African law as medical practitioners or at least not as persons qualified to heal the sick, irrespective of the fact that $84 \%$ of South Africans make use of the services of traditional healers. ${ }^{17}$ Qualifying medical expenses for services rendered to a taxpayer in terms of section 18(1)(b)(i) are limited to the practitioners listed in the subparagraph. Since the promulgation of the Traditional Health Practitioners Act 35 of 2004 (since repealed) and the Traditional Health Practitioners Act 22 of 2007, section 18 of the Income Tax Act has not been amended to incorporate traditional healers into the list of qualifying medical practitioners. Although section 18(1)(b)(i) refers to a "herbalist", it is not clear whether this connotes a "herbalist", as contemplated in the Allied Health Professions Act, ${ }^{18}$ or a traditional healer (who also acts as a herbalist) $^{19}$ in terms of the Traditional Health Practitioners Act. In the absence of a definition in the Income Tax Act and given the fact that the word "herbalist" instead of the phrase "traditionalhealth practitioner" is used it is submitted that "herbalist" in this sense refers to the phytotherapy profession as contemplated in the Allied Health Professions Act. ${ }^{20}$ Furthermore, strictly speaking, the word "herbalist" can only be used as a synonym for a "traditional healer" who makes use only of indigenous plants or herbs and does not extend to a traditional healer who is also a diviner. ${ }^{21}$ Phytotherapy does not resort to divination to heal patients. ${ }^{22}$

16 Jones 2008 Personal Finance Newsletter 16; and Nel and Oberholzer "Tax Matters: Will any of the Medical Expenses Paid by a Taxpayer on Behalf of his Parents Qualify for a Possible Tax Deduction?" 2006 Professional Accountant 10.

17 Lambrecht "Cultural Artefacts and the Oracular Trance States of the Sangoma in South Africa" www.metmuseum.org (accessed on 2010-02-03).

18 Act 63 of 1982.

19 S 1 of Traditionanal Health Practitioners Act 35 of 2004 and 22 of 2007.

20 Phytotherapy is the use of plants and plant products for medicinal purposes.

21 A traditional healer who is also a diviner seeks knowledge or heals patients by supernatural means by calling ancestral spirits or throwing of bones to identify the malign influence of spirits and the casting of spells (spiritual rituals) to bring good luck or health to a patient. 
Although the Income Tax Act fails to define what "registration" is required, all the practitioners listed in section 18(1)(b) are persons who must register in terms of either the Health Professions Act 56 of 1974 or the Allied Health Professions Act 63 of 1982, before they are permitted to practise. It is not clear whether the legislator intended to limit qualifying medical expenses to those which are for services rendered by practitioners who are duly registered in terms of either of these Acts.

On a strict interpretation, qualifying medical expenses would be limited to services rendered by a practitioner who falls within one of the categories listed in section 18(1)(b)(i) and who is duly registered either in terms of the Health Practitioners Act or the Allied Health Professions Act.

It is submitted, however, that a more expansive interpretation should be adopted.

The principles of the interpretation of statutes will now be discussed to determine whether traditional health practitioners may be regarded as included in the categories of health practitioners listed in section 18(1)(b)(i).

\section{A liberal/expansive interpretation}

It is submitted that, if an expansive interpretation is adopted, the phrase "duly registered" in section 18(1)(b)(i) can be interpreted to mean that the practitioner is required to be registered in terms of any Act that specifically regulates that particular category of practitioner.

\section{Traditional Health Practitioners Act 35 of 2004}

The Traditional Health Practitioners Act 35 of 2004 was promulgated on 11 February 2005 to recognize traditional healers as health professionals and to regulate the traditional-healing profession in South Africa. In terms of section 2, the purpose of the Act is to establish the Interim Council for Traditional Practitioners in South Africa, to provide for the registration, training and practices of traditional healers, and to serve and protect the public who make use of such healers. This Act was, however, declared unconstitutional on 17 August 2006 in Doctors for Life International v Speaker of the National Assembly CCT 12/05 due to parliament's failure to follow due processes in passing the Bill. ${ }^{23}$

\section{Traditional Health Practitioners Act 22 of 2007}

On 30 April 2008 the Traditional Health Practitioners Act 22 of 2007 was promulgated to replace the Traditional Health Practitioners Act 35 of 2004, which had been declared unconstitutional.

The purpose of the first-mentioned Act is to establish the Interim Council for Traditional Practitioners in South Africa, to provide for the registration,

22 Unknown author What Do Phytotherapists Do? Obtained from www.herbalpractitionerssa. co.za (accessed on 11-06-2010).

23 Part 1 Memorandum on the Objects of the Traditional Health Practitioners Bill. 
training and practices of traditional healers, and to serve and protect the public who make use of these healers. ${ }^{24}$ The Act applies to the traditionalhealth practitioners' profession in South Africa. ${ }^{25}$

In terms of section 21(1) no person may practise as a traditional healer if he or she is not registered as such in terms of the Act. Section 18(1)(b)(i) of the Income Tax Act requires that the medical practitioner in the listed categories must be "duly registered". As was noted earlier, section 18(1)(b)(i) does not specify how and in terms of which Act the practitioner must be so registered. It is submitted that "duly registered" should be interpreted as meaning duly registered in terms of the Act which regulates the particular profession for which a qualifying medical-expense deduction is being sought. On this interpretation, a traditional-health practitioner would therefore satisfy the requirement of being "duly registered" if he is registered as such in terms of section 21(1) of the Traditional Health Practitioners Act which regulates the registration of traditional healers.

However, traditional-health practitioners are not listed in section 18(1)(b)(i) and, arguably, cannot comply with the three-tier test, irrespective of whether they are "duly registered" in terms of the Traditional Health Practitioners Act. It is, however, submitted that, even as it is presently expressed, section $18(1)(b)(i)$ can be interpreted as including traditional healers in the stated categories of medical practitioners, and that a statutory amendment is not required to bring this about.

The eiusdem generis rule may be applied to the interpretation of sections made up of a general phrase preceded (or followed) by a class or genus of words with a limiting effect where the section is found to be ambiguous or unclear. ${ }^{26}$ This rule is usually applied to include a word where the list or genus has not been exhausted. ${ }^{27}$ The eiusdem generis rule is, however, a restrictive approach to interpretation where the general phrase (for example "or similar place of business") is limited to the genus or listed preceding words. ${ }^{28}$ The eiusdem generis rule can be applied only where a distinct genus or category is present. ${ }^{29}$ In other words, it is the legal equivalent of the idiomatic phrase "aan jou vriende word jy geken", as "you are judged by the company you keep". The categories of practitioners in section 18(1)(b)(i) are not preceded or followed by a general

\footnotetext{
S 2(a)-(c) Act 22 of 2007.

S 3(a)-(b) Act 22 of 2007.

Du Plessis Re-interpretation of Statutes (2002) 236.

Botha Wetsuitleg 3ed (1998) 128-129.

Cockram Interpretation of Statutes 3ed (1987) 153; Du Plessis 234-235; Moodley v Scottsburgh/Umzinto North Local Transitional Council 20004 SA 524 (D) 531; First National Bank of SA Ltd v Rosenblum 20014 SA 189 (SCA) 196; Rauties Transport (Edms) Bpk v Voorsitter, Plaaslike Padvervoerraad, Johannesburg 19834 SA 146 (W) 159-160; and S v M 19773 SA 379 (C) 381.

29 Craies Statute Law 7ed (1971) 181; Cockram 153; Skotness v South African Library 19972 SA 770 (SCA) 775; S v Kohler 19791 SA 861 (T) 862; S v Mkhwanazi 19874 SA 171 (T) 176-177; S v Venter 19791 SA 135 (T) 137; Adrich Investment Holdings CC $v$ Triple Thirteen Investments Shareblock (Pty) Ltd 19942 SA 81 (C) 89; S v M supra 381; Commissioner of Taxes v C 19812 SA 298 (ZA) 301; Oelofse v Santam Versekeringsmaatskappy Bpk 19823 SA 882 (A) 884; Buglers Post (Pty) Ltd v Secretary for Inland Revenue1974 3 SA 28 (A) 34-35; and Grobbelaar v Van der Vyver 19541 SA 248 (A) 254

30 Botha 128; and Steyn Die Uitleg van Wette 5ed (1981) 30.
} 
phrase as would be required to bring the eiusdem generis rule into play and, strictly speaking, the rule cannot be applied to include a word of the same genus. If, however, words are "judged by the company they keep", irrespective of a general phrase, the eiusdem generis rule can be applied where the words have not exhausted the genus. The genus or common denominator of the terms listed in section 18(1)(b)(i) is "medical practitioner" - which can be paraphrased as "a person who practises medicine".

The question then arises whether a traditional-health practitioner can be said to "practise medicine"? In order to answer this question, the duties of a traditional-health practitioner will now be discussed.

\section{$31121 \quad$ What does a sangoma do?}

In order to determine whether a traditional-health practitioner "practises medicine", a comparison needs to be drawn between traditional and conventional healing practices.

It is common cause that one consults a "doctor" (in the conventional sense) if one has a physical (or possibly, mental or psychological) ailment. Conventional "medical practitioners" try to resolve a physical ailment by prescribing laboratory-tested medicine or treatments or may even recommend surgery. In the case of a psychological ailment, a "psychologist" will apply different psychological treatments_(generally accepted by Western psychologists) or prescribe laboratory-tested medicine.

Since the Health Practitioners Act and the Allied Health Practitioners Act fail to define what is meant by a "medical practitioner", the ordinary meaning of the words "medical practitioner" should (it is submitted) be adopted to determine whether a traditional healer can properly be included within this phrase. ${ }^{31}$ A "medical practitioner" can be defined as:

"1. an authorized practitioner of medicine, as one graduated from a college of medicine or osteopathy and licensed by the appropriate board;

2. one who practises medicine as distinct from surgery.,32

It is submitted that the duties of a medical practitioner in terms of the Allied Health Practitioners Act and the Health Practitioners Act should be examined to draw a comparison between the professional duties pertaining to medical practitioners in terms of the afore-mentioned Acts and the professional duties of a traditional healer. For purposes of the Allied Health Professions Act and the Health Practitioners Act, a practitioner may "physically examine, diagnose, and treat or prevent physical and mental disease or illness or deficiencies in humans, prescribe or dispense medicine and/or provide or prescribe treatment for such disease, illness or deficiencies in humans."

The literature indicates that traditional healers generally resort to alternative forms or methods of healing, and their duties in a community are

31 Cockram 155, Botha 92; and Du Plessis 113-114.

32 http://medical-dictionary.thefreedictionary.com/medical+practitioner (accessed on 2008-0423).

33 S 2(a) of Act 63 of 1982; and s17(1)(b) of Act 56 of 1974 (author's own emphasis). 
not limited to healing physical or psychological ailments. In addition, a traditional healer may profess to -

- call upon ancestors and spirits to predict the future or indicate the source of ill-fortune $;^{34}$

- locate lost or stolen goods by throwing bones (commonly known as dolosgooi) $;^{35}$

- bring back lost lovers or put spells on cheating lovers; ${ }^{36}$

- chase away the Tokoloshe (believed to be a devil-like figure who impregnates woman at night);

- ward off bad spells, misfortune, ill-luck and cast good spells for the patient; ${ }^{38}$ and

- use indigenous South African plants, animal matter and sometimes human organs/limbs or human remains to treat ailments. ${ }^{39}$

The Traditional Health Practitioners Act 22 of 2007 does not specify the duties of a "traditional health practitioner". However, section 49 makes provision for criminal offences if a person, not qualified or registered in terms of the Act:

"(b) for gain -

(i) physically examines any person;

(ii) performs any act of diagnosing, treating or preventing any physical defect, illness or deficiency in respect of any person;

(iii) advises any person on his or her physical or mental state;

(iv) by reason of information provided by any person or obtained from such person in any manner whatsoever -

(aa) diagnoses such person's physical or mental state;

(bb) advises such person on his or her physical or mental state;

(cc) supplies or sells to or prescribes for such person any traditional medicine or treatment;

(v) prescribes or provides any traditional medicine, substance or thing; or

34 http://www.knet.co.za/shakaland/Sangoma.htm (accessed on 2008-05-21); Lambrecht www.metmuseum.org (accessed on 2010-02-03); Sodi "Taile, The Traditional Healer: A Psychologist's View of Healing in a Northern Sotho Community: Indigenous Knowledge Systems, Health, Illness and Healing" 2009 Indilinga African Journal of Indigenous Knowledge Systems 127-137.

35 lbid.

http://www.traditionalhealer.co.za/healing.asp (accessed on 2008-05-21).

http://scifipedia.scifi.com/index.php/Tokeloshe; http://www.mostparanormal.co.uk/tokeloshe ---cryptozoology.htm (accessed on 2008-05-21).

$38 \mathrm{http}: / /$ www.nativedoctor.co.za/ (accessed on 2008-05-21); Ingle "An Appraisal of the African Traditional Healing System" 2007 Journal for New Generation Sciences 34; and Meissner "The Traditional Healer as Part of the Primary Health Care Team?" 2004 South African Medical Journal 901.

39 Pretorius Traditional Healers http://www.hst.org.za/uploads/files/chapter18_99.pdf (accessed on 2008-05-21); Lambrecht www.metmuseum.org (accessed on 2010-02-03); Rakuambo, Du Toit, Soundy and Olivier "Indigenous Knowledge System of Bush Tea from the Local People in Venda" 2009 Indilinga African Journal of Indigenous Knowledge Systems 158-162; and Mufamadi "Cross Cultural Dilemmas in the Management of HIV AIDS: The Role of African Traditional Healers: Indigenous African Healing Practices" 2009 Indilinga African Journal of Indigenous Knowledge Systems 31. 
(vi) performs any other act specially pertaining to the profession."

It may be inferred from section 49 that, in the main, traditional-health practitioners heal or treat illnesses or disabilities by using traditional-healing rituals and dispensing traditional medicine. Section 49 does not specifically include divination (spirit calling or the reliance on supernatural powers) in a traditional healer's duties but the words "performs any other act specifically pertaining to the profession" in section 49(b)(vi) could be interpreted to refer to the powers of divination (or supernatural powers) of traditional healers.

However, since the Act does not specifically include "divination", it seems to contemplate that, primarily at least, a traditional healer examines or diagnoses the patient in order to treat or prevent any physical or mental illness or disability. In this sense, there is no difference between the primary functions of a conventional medical practitioner and those of a traditionalhealth practitioner. It can therefore be concluded that the meaning of "traditional-health practitioner" and "medical practitioner" stems from the same genus. It is submitted that the expression "traditional health practitioner" could be interpreted as included in the list of "practitioners" in section $18(1)(b)(i)$ in terms of the eiusdem generis rule in that the genus "medical practitioner" is not exhausted by the existing words in the list. Alternatively, it is arguable that, since the Income Tax Act fails to define "medical practitioner", a traditional-health practitioner can be included within the ambit of the expression "medical practitioner" on the basis of the primary functions of medical practitioners, as contemplated in the Health Professions Act, the Allied Health Professions Act and the Traditional Health Practitioners Act.

\section{Professional services rendered or medicine supplied}

\section{Professional services}

The third aspect of the three-tier test to determine whether a taxpayer is entitled to a qualifying medical expense deduction is whether professional services were rendered or whether medicines were supplied to the taxpayer. In the absence of a statutory definition of "professional services", it is submitted that this expression implicitly connotes the application of knowledge and skill (which - it may be presumed - the relevant practitioner acquired by completing the requisite qualifications and/or training for that specific field of medical practice) to heal or attempt to heal the patient's ailments. Although section 18(1)(b)(i) does not expressly require a medical practitioner to have obtained a specific qualification it seems to be implicit that a duly registered medical practitioner would have obtained some sort of qualification (from a an accredited institution or authority) in order to satisfy the registration requirements of the Act that regulates the profession, and could not, for example, simply be self-educated. By implication, therefore, the rendering of "professional services" requires skill or knowledge that can be obtained only by completing a course of training or some other qualification.

$40 \quad S$ 49(1)(b). 
In terms of section 21(2)(b) of the Traditional Health Practitioners Act, one of the statutory requirements to be registered as a traditional healer is that the application should be accompanied by proof of the applicant's qualifications. In terms of section 22, the Minister of Health can prescribe the minimum qualification or qualifications that have to have been obtained from an accredited institution by virtue of examination or training in order to qualify as a registered traditional healer. The same position applies to medical practitioners registered under the Health Professions Act ${ }^{41}$ as well as homeopaths, chiropractors or any other allied health practitioners who are registered in terms of the Allied Health Profession $\mathrm{Act}^{42}{ }^{42}$ and pharmacists who are registered in terms of the Pharmacy Act. ${ }^{43}$ In the case of traditional healers, no such accredited schooling or examinations are available and the Minister has yet to declare the necessary qualifications. ${ }^{44}$ In the case of medical practitioners, pharmacists, homeopaths, and so on, a qualification in the form of a degree or diploma (at tertiary level) obtained from a qualified institution is needed.

Presently, in absence of any regulation to the contrary, traditional healers can qualify as such by attending an initiation school, or, as is generally the case, gain their knowledge from another traditional healer who acts as principal in an apprenticeship. The apprenticeship can last for between one and five years and a person will be regarded as a true traditional healer only once he or she has gained the respect of the community as a healer. ${ }^{45}$ Qualifications (according to tradition) also differ in different South African cultures. In some cultures a respectable inyanga (that is to say, a sangoma with spiritual-healing powers) needs no formal qualification (for example, schooling) but according to tradition, ancestral powers or powers to be "called by the spirits" or to be able "to call the spirits" are sufficient for someone to be qualified as a traditional healer (and perceived by the community as a traditional healer of excellence) ${ }_{i 7}^{46}$ The healers of other South African cultures do not practise spirit calling ${ }^{47}$ or divination but regard their traditional healers as herbalists. ${ }^{48}$ The latter are trained in the different healing powers of plants and they generally dispense indigenous herbs,

\footnotetext{
S 24 of Act 56 of 1974 .

S 16B(1) of Act 63 of 1982 .

$S 28(1)(a)$ and (b) of Act 53 of 1974

44 Unknown author "The impact of the Traditional Health Practitioner Act" (06 October 2006) http://www.wwb.co.za/wwb/view/wwb/en/page157?oid=5372\&sn=Detail (accessed on 200805-20).

45 Legal Status of Traditional Medicine and Complementary/Alternative Medicine: A Worldwide Review $2001 \mathrm{http}: / /$ www.who.int/medicinedocs/fr/d/Jh2943e/\#Jh2943e.4.38 (accessed 2008-05-20); Hess "Traditional Healers in South Africa" 1998 HST Update 6; Piliso "Belgian Training as Xhosa Sangoma" 1999 Dispatch obtained from www.dispatch.co.za (accessed 2010-02-03).

46 Kale "South Africa's Health: Traditional Healers in South Africa: A Parallel Health Care System." 1995 BMJ 1882-1885 obtained from http://www.bmj.com/cgi/content/full/310/ 6988/1182 (accessed on 2008-05-20); Lambrecht www.metmuseum.org (accessed on 2010-02-03).

47 The use of supernatural powers to communicate with ancestors, deceased persons and or the spiritual world of ghosts and poltergeists.
}

48 Ibid. 
plants or plant material (such as bark, roots, leaves, fruits etcetera) to their patients.

Divination, spirit calling and throwing of bones as a healing power may cause serious problems if it is interpreted as a "professional service" for purposes of section 18(1)(b)(i), as can be illustrated by the following hypothetical examples: Taxpayer $X$ constantly falls and injures himself. $\mathrm{He}$ consults a conventional medical practitioner who diagnoses ostheo-arthritis, an illness which has weakened his hip joint and is causing him to fall. The conventional medical practitioner prescribes physiotherapy and laboratorytested medicine. Taxpayer $X$ will be allowed, in terms of section 18(1)(b)(i) and (iii), to deduct the medical expenses incurred by consulting this medical practitioner, the physiotherapist (as prescribed by the first-mentioned practitioner) and obtaining the medicine (as prescribed by the firstmentioned practitioner) irrespective if he was healed.

Taxpayer $Y$ also suffers from the same ill-health (or the diagnosis would have been the same had he visited a conventional medical practitioner) but consults a traditional healer who believes that Y's deceased wife has put a spell on him which is causing him to fall. The traditional healer performs an ancestral call, ${ }^{50}$ commands the malignant spirits to leave $Y$ (form of exorcism) and supplies $Y$ with plants or animal matter that will ward off the bad spirits. $Y$ believes that he is indeed healed.

Can ancestral calls (like in the hypothetical example above) or divination be regarded, for purposes of the Income Tax Act, as professional services? Section 18(1)(b)(i) does not require the taxpayer to be healed or that the taxpayer should believe that he is healed but requires that professional services must have been rendered or medicine must have been supplied. If the South African Revenue Services (SARS) accepts the interpretation of "medical practitioner" and "professional services" as explained above, it is suggested that SARS publishes an Interpretation Note on medical expenses similar to Publication 502 by the Internal Revenue Services (The revenue services in the United States of America). ${ }^{51}$ This publication contains frequently asked questions on what kind of medical expenses are deductible and what are not. Publication 502 defines "medical expenses" as any medical- or dental-care expense "primarily to alleviate or prevent a physical or mental defect or illness". Excluded from the definition is expenditure that is merely beneficial to general health, such as vitamins or a vacation. ${ }^{52}$ Publication 502 deals extensively with almost every medical expense as well as other expenses relating to medical intervention such as television hearing-aid equipment, transportation costs to and from a clinic or medical professional. ${ }^{53}$ Although a guide to this effect was published by SARS with effect from 1 March 2010, the guide in its current form only lists allowable 
deductions for physically impaired or disabled taxpayers. ${ }^{54}$ It is trite that an Interpretation Note is subordinate to legislation and that it cannot create new law but can merely give an explanation on how the legislation should be interpreted. It should be stressed that an Interpretation Note which contains an extensive list of all the allowable and disallowable deductions for all taxpayers will eliminate most, if not all, of the interpretation controversies of "professional services" at filing level. Interested or aggrieved parties may still wish to challenge the Interpretation Note in a court of law or apply for a private binding ruling. This is, however, a temporary solution considering the cost and time constraints associated with litigation. It is therefore submitted that a definition of "professional services" be inserted in the Income Tax Act. This amendment, it is submitted, will not be effective unless an Interpretation Note, as proposed above, is published in addition to the amendment.

\section{Medicine supplied}

In the absence of a definition of "medicine" in the Income Tax Act for purposes of determining the section 18(1)(b)(i) qualifying medical expenses, it is submitted that the meaning of "medicine" as defined in the Medicine and Related Substances Act 101 of 1965 should be used. This Act defines "medicine" as:

"any substance or mixture of substances used or purporting to be suitable for use or manufactured or sold for use in -

(a) the diagnosis, treatment, mitigation, modification or prevention of disease, abnormal physical or mental state or the symptoms thereof in man; or

(b) restoring, correcting or modifying any somatic or psychic or organic function in man, and includes any veterinary medicine".

It is trite that a traditional healer will generally prescribe traditional medicine to patients. In terms of section 1 of the Traditional Health Practitioners Act "traditional medicine" is defined as:

"an object or substance used in traditional health practice for -

(a) the diagnosis, treatment or prevention of a physical or mental illness; or

(b) any curative or therapeutic purpose, including the maintenance or restoration of physical or mental health or well-being in human beings, but does not include a dependence-producing or dangerous substance or drug;"

A draft Policy on African Traditional Medicine for South Africa ${ }^{55}$ has been adopted by the Ministry of Health for the main purpose of providing a framework for the institutionalization of African traditional medicine in South Africa, regulating the registration and formal training of traditional healers in South Africa, and compiling a complete pharmacopoeia of traditional medicine in Africa. ${ }^{56}$ It is trite that traditional medicine in Africa has developed over thousands of years and can be associated with the diagnosis, treatment and the rehabilitation of a patient's physical,

54 SARS List of Qualifying Physical Impairment or Disability Expenditure in Terms of Section 18(1)(d) of the Income Tax Act, No 58 of 1962 www.sars.gov.za (accessed 2010-07-01).

55 GN 906 GG 31271 of 2008-07-25.

56 Ibid. 
psychological and social well-being. ${ }^{57}$ For this reason the recommendations contained in the policy are inter alia that:

- traditional medicine should be registered and protected;

- a National Institute for Traditional Medicine should be established to promote and establish a research culture for traditional medicine;

- traditional medicine be classified into a) indigenous plants, animals and biological material for domestic use and b) indigenous plants for the commercial production of medicine;

- a complete pharmacopoeia for indigenous traditional African medicine be developed for South Africa;

- a school or faculty for traditional health be established to train and educate future traditional healers enable them to transfer knowledge; and

- the protection and production of indigenous plants that are being used as traditional medicine be promoted. ${ }^{58}$

From the two definitions of "medicine" as contemplated in the Medicines and Related Substance Act and the Traditional Health Practitioners Act, it can be concluded that there is no difference between the purpose of the medicine supplied by a conventional medical practitioner and the medicine supplied by a traditional-health practitioner.

\section{COSMETIC SURGERY AND MEDICAL EXPENSES}

There is no provision in the Income Tax Act that restricts the kind of professional services rendered to a taxpayer that will qualify as an expense deductible under section $18(1)(b)(i)$, since this provision requires only that "professional services" be rendered to the taxpayer by one of the listed categories of persons. As was pointed out earlier in this article, this provision is silent on the nature of the "professional service" and may lead to a situation where a taxpayer can claim a qualifying medical deduction which is not, strictly speaking, an essential or bona fide medical expense.

For example, where an optometrist supplies ordinary contact lenses at a cost of R2 000, but the taxpayer wishes, for purely cosmetic reasons, to purchase colour contact lenses at R3 400 per pair, section 18(1)(b)(i) does not restrict the deduction to the lesser amount even though, strictly speaking, only R2 000 constituted a bona fide medical expenses.

Similar considerations apply where a taxpayer undergoes cosmetic surgery, such as a face-lift, or dental surgery that is purely cosmetic. Again, section 18(1)(b)(ii) does not bar a deduction for such expenses, nor has any reported decision interpreted the Act as doing so.

This may result in privileged taxpayers artificially increasing their qualifying medical expenses by undergoing cosmetic surgery in order to be allowed a greater medical deduction and reducing tax payable. As a matter 
of practice, SARS does not differentiate between expenses incurred in relation to spectacles and expenses for contact lenses.

For example, where the taxpayer chooses to buy contact lenses (which are more expensive than a set of spectacles) just because he/she looks better without spectacles (as opposed to operational reasons), SARS will still allow the cost of contact lenses to determine the qualifying medical deduction. ${ }^{59}$

\section{SERVICES RENDERED BY A PHARMACIST}

Section 18(1)(b)(iii) allows a deduction for fees that were paid to a pharmacist for medicine prescribed by a person listed in section 18(1)(b)(i). If section 18(1)(b)(i) and subparagraph (iii) are read together it seems that if a fee is paid to a pharmacist for professional services rendered by the pharmacist (as distinct from a fee for services) it will not qualify as a deduction. Furthermore, if fees are paid to a pharmacist for over-the-counter medicines (that is to say, medicines not supplied on the prescription of a person listed in section 18(1)(b)(i)) supplied to the taxpayer, it will not qualify as a deduction. For example: $X$ suffers from a headache and goes to a pharmacist who suggests (pharmacists do not issue prescriptions) and dispenses a schedule $2^{60}$ painkiller. The dispensing fee paid to the pharmacist will not qualify as a deductible medical expense. However, if $X$ receives treatment from a medical practitioner as listed in subparagraph (i), who prescribes the same schedule 2 painkillers which are then dispensed by the pharmacist in terms of subparagraph (iii), both the medical practitioner's consultation fee and the pharmacist's dispensing fee will qualify as qualifying medical expenses. ${ }^{61}$ It is submitted that the legislature did not intend the above strict differentiation. It is trite that pharmacists may not perform surgery or specialist treatment to patients similar to that of other medical practitioners or specialists. However, where a taxpayer pays a pharmacist for professional services rendered, for which the pharmacist is qualified and statutorily authorized to do, the taxpayer should (it is submitted) be entitled to a medical deduction, thus making the differentiation set out above completely irrational.

In terms of section 13(1) of the Pharmacy Act 53 of 1974, no person may "provide the services which form part of the services specially pertaining to the scope of practice of a pharmacist or assist therewith" unless that person is duly registered in terms of the Act. The Pharmacy Act, however, fails to identify or define the "services specially pertaining to the scope of practice of a pharmacist".

It is submitted that the Rules Relating to the Services for which a Pharmacist may Levy a Fee and Guidelines for Levying such a Fee or

59 Tax Guide on the Deduction of Medical Expenses $21 \mathrm{http}: / /$ www.sars.gov.za/ uploads/images/0_Deduction_of_Medical_Expenses.pdf (accessed on 2008-06-02).

60 Schedules 0-2 medicines may be dispensed by a pharmacist without a prescription. Schedule 3-9 medicines may only be dispensed by a pharmacist if a prescription was issued by a medical practitioner or dentist. S 22A(3), (4) and (5) Medicines and Related Substance Act 101 of 1965.

61 Jones 2008 Personal Finance Newsletter 16. 
Fees ${ }^{62}$ should be consulted to determine what these services entail. In addition to dispensing, preparing and compounding medicine, a pharmacist may also perform blood-pressure, blood-sugar and other tests on a patient for a prescribed fee ${ }^{63}$ In summary it can be said that a pharmacist may physically examine ${ }^{64}$, diagnose ${ }^{65}$, treat disease or illness in humans ${ }^{66}$, dispense medicine ${ }^{67}$ and/or provide or prescribe treatment ${ }^{68}$ for such disease, illness or deficiencies. In essence the duties of a pharmacist are the same as that of a medical practitioner for purposes of the Health Practitioners Act or Allied Health Practitioners Act except for those duties requiring specialist training.

It can, further to the above arguments, be argued that the term "medical practitioner" means "a person who practices medicine". ${ }^{69}$ Medicine is defined as "the science or practice of the diagnosis, treatment and prevention of disease (distinct from surgery). ${ }^{, 70}$ When a pharmacist performs professional services such as blood-sugar tests or compound and dispense medicine, he is practising the science of the "diagnosis, treatment and prevention of disease". A pharmacist could therefore fall within the wider meaning of the words "medical practitioner" as listed in section 18(1)(b)(i).

In conclusion it is submitted that, on a proper interpretation, section 18(1)(b)(iii) grants a deduction for non-prescription medicine supplied or professional services rendered by a duly registered pharmacist.

\section{CONSTITUTIONAL ASPECTS}

In the light of the Constitution, it is unlikely that an intention by the legislator to specifically exclude traditional-health practitioners from the list of medical practitioners in section 18(1)(b)(i), and subsequently to deny a qualifying medical-expense deduction to a taxpayer who consulted a traditional healer (as apposed to have consulted a conventional medical practitioner) can be upheld. Section 9(3) of the Constitution states that no-one may directly or indirectly unfairly be discriminated against based on inter alia religion, culture or race. But where the discrimination is unavoidable or necessary, the question arises whether the discrimination can be regarded as "fair and just in an open and democratic society" in terms of section 36(1) of the Constitution.

In 1994, the Katz Commission made recommendations on tax reform in South Africa and highlighted certain provisions in South Africa's tax laws that

\footnotetext{
The South African Pharmacy Council Board Notice 160 of 2009 GG 32749.

Item 8 Annexure A: The South African Pharmacy Council Board Notice 160 of 2009 GG 32749 .

Annexure B: The South African Pharmacy Council Board Notice 160 of 2009 GG 32749.

65 Ibid.

Ibid.

A pharmacist may dispense non-prescription medicine without a prescription.

68 Annexure B: The South African Pharmacy Council Board Notice 160 of 2009 GG 32749.

69 www.websterdictionary.org (accessed on 2010-11-04).

70 Concise Oxford English Dictionary 2008.
} 
were prima facie unconstitutional. ${ }^{71}$ Although the Commission's first report was based on the interim Constitution ${ }^{72}$ it applies to the 1996 Constitution as the scope and purpose of the fundamental rights contained in The Bill of Rights in both these Acts are similar. The Commission highlighted the then current discrimination based on age in the Income Tax Act as it then stood (that is, the difference in rebates and allowable medical deductions between persons over the age of 65 and persons under the age of 65) and came ${ }^{73}$ to the conclusion that age-based discrimination can be fair from a policy point of view as elderly persons find it harder to make ends meet and an extra tax incentive can be seen as poverty relief. $^{74}$ Although the Commission recommended that this type of discrimination should be reconsidered, the legislator has, to date, failed to set aside age-discrimination tax rules.

Van Schalkwyk ${ }^{75}$ is of the opinion that age-related discrimination in terms of sections 6(2)(b) and 18(2)(a) is fair in terms of section 36 of the final Constitution. In the light thereof she further opines that no amendment in this regard was required. ${ }^{.6}$ No reported decisions of the Tax Court or the High Court have dealt with discrimination by Tax legislation based on the Constitutionally entrenched rights in terms of section 9(3) of the Constitution. It could be argued that the discrimination against taxpayers who consult traditional healers is fair from a policy point of view where the traditional healer performs ancestral calls, throws bones or casts spells to ward off bad spirits, which cannot be classified as "medical" professional services. This argument is, however, aimed at the type of services rendered by a selected few traditional healers and not at the concept of traditional healer as a medical practitioner. It is therefore submitted that the discrimination against a taxpayer who consulted a traditional healer (purely on the basis that a traditional healer is not a medical practitioner) cannot be justifiable in terms of section 36. As submitted earlier, a definition of "professional services" is needed to determine what type of services qualifies for a medical deduction. Discrimination in the form of a disallowance of a deduction based on the type of services rendered could be justified from a policy point of view.

\section{CONCLUSION}

The taxpayer who claims to be entitled, in terms of section 18 of the Income Tax Act, to a deduction for a medical expense bears the onus of showing that the deduction being sought is indeed allowable. ${ }^{77} \mathrm{~A}$ taxpayer who has consulted and paid a traditional healer will therefore have to prove that the latter is (a) "duly registered"; (b) is a "medical practitioner" within one of the

71 Commission of Inquiry into Certain Aspects of the Tax Structure of South Africa Interim Report of the Commission of Inquiry into Certain aspects of the Tax Structure of South Africa (1994) 67-83.

72 Act 200 of 1993.

73 Commission of Inquiry into Certain Aspects of the Tax Structure of South Africa 72-73.

$74 \mathrm{Ibid}$; Van Schalkwyk "Constitutionality and the Income Tax Act Revisited" 2004 Meditari Accountancy Research 186.

75 Ibid.

76 Ibid. Van Schalkwyk 2001 Meditari Accountancy Research 294.

77 Oosthuizen v Standard Credit Corporation Ltd 19933 SA 891(A) 907; and Commissioner of Inland Revenue v Nemojim (Pty) Ltd 19834 SA 935 (A) 946. 
categories listed in section 18(1)(b)(i) who; (c) rendered "professional services" to the taxpayer.

It was submitted, above, that a traditional healer complies with the requirement of being duly registered if that person is registered in terms of the Traditional Health Practitioners Act. A traditional healer, it is further submitted, is a "medical practitioner", as widely interpreted, even though the words "traditional health practitioner" are not included in the categories of practitioners listed in section 18(1)(b)(i). Except for divination, ancestral calling, throwing of bones and identifying the malign influence of spirits, the services rendered by a traditional healer and a conventional medical practitioner are the same. It is submitted that, if this issue were to be tested in the Tax Court or on further appeal, a taxpayer would succeed in establishing, on an expansive and liberal interpretation, an entitlement to deduct, in terms of section 18 of the Income Tax Act, expenses incurred for services rendered or medicines supplied by a traditional healer, duly registered under the Traditional Health Practitioners Act.

It is further submitted that, if this is indeed the proper interpretation of section 18, there is no need to amend section $18(1)(b)(i)$ to expressly include traditional-health practitioners in the category of practitioners.

However, from a policy point of view, it should be noted that the type of professional services rendered by a traditional-health practitioner and the method of rendering the professional service might not qualify as professional medical's services for purposes of calculating a qualifying medical-expense deduction. For example, a taxpayer pays the traditional healer to "gooi dolos" to predict the future or to call upon the spirits to indicate what is causing his illness. Can this still be seen as professional services for purposes of calculating qualifying medical expenses? It is submitted that "professional services" for purposes of a medical deduction, does not denote the reliance upon supernatural powers or the prediction of future. If SARS does not, as a matter of practice, differentiate between the healing or medical services of traditional healers (those similar to that of a herbalist) and the more spiritual services (those of a diviner or inyanga) when interpreting "professional services", the taxpayer will be allowed to deduct the fees of a sangoma as qualifying medical expenses even if the services rendered by the sangoma merely entailed predicting the future by throwing bones. This could lead to an untenable situation which can be illustrated by the following examples:

$X$ feels depressed and consults a traditional healer. The traditional healer throws the bones and predicts that $X$ will soon win money. $X$ is relieved from depression. $X$ may deduct the fees paid to the traditional healer because the traditional healer is a medical practitioner in the wider sense who performed "professional services".

Author's own emphasis.

Sangomas throw the knuckle bones of animals on an animal skin. The location of each knuckle bone predicts the client's future or shows where his/her ill-health is situated. Knuckle bones are also used to call the spirits who will then turn the bones in a more favourable direction and subsequently heal the client of ailments. http://www.dolos.co.za/; http://www.southafrica.info/business/trends/innovations/dolosse.htm (accessed on 2008-0522). 
$Y$ feels depressed and consults a clairvoyant. The clairvoyant uses tarot cards to predict that $Y$ will soon win money. $Y$ is relieved from depression. $Y$ cannot deduct fees paid to the clairvoyant because the clairvoyant is not a medical practitioner as listed.

Further to the problem of interpreting "professional services", in the absence of any legislation, Interpretation Note or guide to the contrary, it is submitted that a taxpayer would be entitled to a deduction for cosmetic procedures. It is submitted that cosmetic procedures, although medical in nature, should not qualify as professional medical services. The purpose of the medical deduction incentive is to encourage taxpayers to pay for their own medical expenses and not to rely on state-funded medical services. The incentive, it is submitted, is not intended to allow taxpayers to claim medical deductions for cosmetic procedures to avoid paying taxes. It is suggested that, in addition to the insertion of a definition of "professional services" in the Income Tax Act, SARS issue an Interpretation Note which extensively deals with all types of allowable and disallowed medical expenses in a "frequentlyasked questions" format.

The differentiation, set out above, between services and medicines supplied by a medical practitioner as listed in section 18(1)(b)(i) and a pharmacist nears hairsplitting. It can be anticipated that more taxpayers will consult pharmacists (for purely economic reasons) for professional services (for which they are qualified and statutorily authorized to render) in the light of the adoption of a pharmacist-fee structure by The Pharmacy Council Board. ${ }^{80}$ By disallowing a medical deduction to taxpayers who consulted a pharmacist would not promote the purpose of the incentive to encourage taxpayers not to rely on state-funded medical services. It is therefore submitted that a pharmacist is a medical practitioner in the wider sense and a taxpayer should be able to seek a deduction for fees paid to a pharmacist for professional services or schedule 2 medicines supplied upon proper interpretation of "medical practitioner".

That said, a taxpayer who seeks a medical deduction (if denied) under the Act, as it currently stands, for professional services rendered or schedule 2 medicines supplied by a pharmacist, or for professional services rendered by a traditional healer, will have to object against the assessment or take the matter on appeal. This might not be worth the taxpayer's while considering the cost of litigation. If the Tax Court (or High Court) never gets the opportunity to investigate the wider interpretation, as proposed, it is submitted that the majority of taxpayers will continue to be discriminated against based on their culture, belief or financial ability to afford medical services from conventional medical practitioners. In the light thereof it is submitted that the legislator reviews section 18 as it currently stands to incorporate (in addition to the proposed insertion of a definition of professional services above), in the interpretation of "medical practitioner", the professional services rendered by traditional healers and pharmacists.

80 The South African Pharmacy Council Board Notice 160 of 2009 GG 32749. 